\title{
Percepção de médicos sobre fatores de atração e fixação em áreas remotas e desassistidas: rotas da escassez
}

\author{
I 1 Ana Cristina Sousa Van Stralen, ${ }^{2}$ Alice Werneck Massote, \\ ${ }^{3}$ Cristiana Leite Carvalho, ${ }^{4}$ Sabado Nicolau Girardi I
}

Resumo: A escassez e a má distribuição geográfica de médicos são problemas graves e persistentes no Brasil. Conhecer o que atrai e principalmente o que retém esses profissionais em áreas remotas e desassistidas é essencial para orientar políticas públicas. Neste trabalho, investigaramse os principais fatores de atração e retenção em munícipios que apresentavam escassez de médicos, compondo as denominadas "rotas da escassez". Foram realizadas entrevistas em profundidade com 51 médicos em 10 rotas que abrangeram as cinco regiões do Brasil. Na análise de conteúdo, foram identificadas seis categorias: remuneração, vínculo de trabalho, condições de trabalho, fatores profissionais, fatores locais e fatores pessoais, divididas em 27 subcategorias, com destaque para os itens de salário, flexibilidade da jornada de trabalho, infraestrutura da unidade de saúde, origem do profissional, infraestrutura e opções de lazer do município. Os resultados evidenciam a importância de combinar diferentes incentivos, financeiros e não financeiros, para atrair médicos para áreas remotas e desassistidas.

> Palavras-chave: escassez; médicos; atenção primária; saúde pública.

\author{
1 Universidade Federal de \\ Minas Gerais, Faculdade de \\ Medicina, Núcleo de Educação \\ em Saúde Coletiva (NESCON). \\ Belo Horizonte-MG, Brasil \\ (anastralen@gmail.com). \\ ${ }^{2}$ Universidade Federal de \\ Minas Gerais, Faculdade \\ de Medicina, NESCON. \\ Belo Horizonte-MG, Brasil \\ (alicewmassote@gmail.com). \\ ${ }^{3}$ Universidade Federal de \\ Minas Gerais, Faculdade \\ de Medicina, NESCON. \\ Belo Horizonte-MG, Brasil \\ (cristianalcarvalho@gmail.com). \\ ${ }^{4}$ Universidade Federal de \\ Minas Gerais, Faculdade \\ de Medicina, NESCON. \\ Belo Horizonte-MG, Brasil \\ (sabadogirardi@gmail.com).
}

Recebido em: 11/11/2015 Aprovado em: 25/09/2016 
A escassez de médicos tem sido apontada na maioria dos países como um problema grave e persistente ao longo do tempo, resistente às mais variadas estratégias adotadas para o seu enfrentamento (WHO, 2010). No Brasil, a situação não é diferente. Nas duas últimas décadas, vários estudos apresentaram evidências de escassez de médicos (PÓVOA; ANDRADE, 2006; FGV, 2008; CAMPOS; MACHADO, 2009; GIRARDI et al., 2011; EPSM, 2014). Em 2010, ano anterior à pesquisa, o país apresentava uma taxa de 1,91 médicos por mil habitantes (CREMESP, 2015), inferior a países como a Austrália $(3,3)$, Bélgica (2,9), Estados Unidos (2,5) e Espanha (3,8) (OECD, 2014).

Um fator agravante da situação é a desigualdade distributiva dos médicos, reflexo da preferência desses profissionais em se fixar em cidades de maior porte populacional, localizadas em regiōes economicamente mais desenvolvidas. Além de oferecerem maiores oportunidades profissionais e educacionais, elas oferecem outros atrativos importantes, como lazer e serviços para o médico e sua família. Logo, são as regiões mais carentes e/ou remotas que apresentam maior dificuldade de atração e fixação de profissionais médicos (GIRARDI et al., 2011).

Estratégias para reduzir ou erradicar a escassez de médicos têm sido relatadas em vários países com diferentes graus de sucesso. O Canadá e os Estados Unidos figuram entre esses países, com inúmeros programas e estudos voltados para essa questão, a exemplo da designação de Underserviced Area Program (UAP) e das Health Professional Shortage Area (HPSA) que se revelaram bastantes úteis, respectivamente, na orientação dos processos de alocação de recursos (profissionais e programas) destinados a aliviar as situações de carência das comunidades, e na definição de prioridades de acordo com a intensidade do problema por elas vivenciado (GAO, 2006).

O governo brasileiro tem igualmente lançado mão de políticas e estratégias para enfrentar o problema de atração e fixação de profissionais médicos. São elas: as políticas de extensão de cobertura e de interiorização da medicina, como o Programa de Interiorização das Ações de Saúde (PIASS) e a implantação de internatos rurais nas graduações da área da saúde; o sistema de abatimento das dívidas contraídas para o financiamento do curso de graduação, por meio do Fundo de Financiamento Estudantil (FIES); e a Estratégia Saúde da Família 
(ESF), política que orienta a oferta pública de serviços de atenção básica em saúde no país e constitui, talvez, o melhor exemplo de expansão da cobertura de médicos no território nacional, apesar de não ter sido desenhada especificamente com este objetivo. Além disto, os gestores municipais adotam diversos tipos de incentivos na tentativa de atrair e fixar médicos em seus respectivos municípios, como o aumento dos salários e a flexibilização da jornada de trabalho (MACIEL FILHO, 2007; GIRARDI et al., 2011).

Em 2011 e 2013, o governo lançou dois programas de provimento, o Programa de Valorização do Profissional da Atenção Básica (PROVAB) e o Programa Mais Médicos (PMM), que, diante da persistência de postos vacantes em áreas remotas e desassistidas, recruta, além de médicos formados no Brasil e/ou registrados nos Conselhos Regionais de Medicina (CRM), médicos graduados no exterior, brasileiros e de outras nacionalidades. Esses programas buscam, por meio de medidas e incentivos financeiros e não financeiros, atrair médicos para áreas remotas e desassistidas (BRASIL, 2011; BRASIL, 2013).

De qualquer forma, medidas únicas e isoladas não têm se mostrado suficientes para resolver o problema de escassez e má distribuição de médicos. Faz-se necessário conhecer os fatores que, combinados, podem equacionar e superar as dificuldades relacionadas à atração e fixação de profissionais médicos em áreas que enfrentam escassez. O objetivo deste estudo foi, portanto, identificar os fatores que contribuem para atrair e reter médicos em áreas remotas e desassistidas do país.

\section{Metodologia}

Trata-se de um estudo descritivo e exploratório com abordagem qualitativa, em que se buscou pesquisar em profundidade quais são os principais fatores que atraem e retêm médicos em áreas remotas e desassistidas. $\mathrm{O}$ estudo envolveu três etapas: a definição das áreas e municípios a serem investigados, que têm como característica comum a escassez de médicos, compondo as denominadas "rotas da escassez"; a realização de entrevistas em profundidade com médicos dos municípios selecionados; e a análise das entrevistas e discussão dos dados.

Para a definição dos municípios, foram combinados dados de dois estudos. O primeiro se refere a um Índice de Escassez de Médicos em Atenção Primária em Saúde (EPSM, 2012), que mede a escassez de médicos da Atenção Primária 
em Saúde (APS) nos municípios brasileiros. A ele, são atribuídos cinco graus de intensidade: escassez severa, alta, moderada, baixa e traços. Para medir os níveis de escassez, o índice leva em consideração, na sua composição, as seguintes dimensōes/indicadores:

i. Oferta de médicos em APS, medida pelo número de clínicos, pediatras e médicos de saúde da família por habitante (CNES);

ii. Necessidades de saúde, medida pela Taxa de Mortalidade Infantil;

iii. Condição socioeconômica da população, medida pelo número de domicílios elegíveis ao Programa Bolsa Família.

Em dezembro de 2010, o Índice de Escassez permitiu identificar um total de 1.304 municípios brasileiros com escassez de médicos em APS. Entre esses, 66 tinham escassez alta e três, escassez severa (EPSM, 2012).

O segundo estudo, denominado Regiōes de Influência das Cidades, do Instituto Brasileiro de Geografia e Estatística (IBGE), apresenta a classificação dos centros da rede urbana brasileira por meio da oferta e procura de diferentes tipos de serviços e equipamentos públicos e privados, tais como deslocamentos para internações hospitalares, áreas de cobertura de canais de televisão, informaçôes de ligaçôes aéreas, oferta de ensino superior, diversidade de atividades comerciais e de serviços, entre outros. Para delimitar as áreas de influência dos centros, o IBGE pesquisou a intensidade das ligações entre as cidades, com base em dados secundários e dados obtidos por meio do questionário específico da pesquisa, combinados para definir as regiōes de influência dos centros urbanos, categorizados em diferentes níveis (IBGE, 2008) (Quadro 1). 


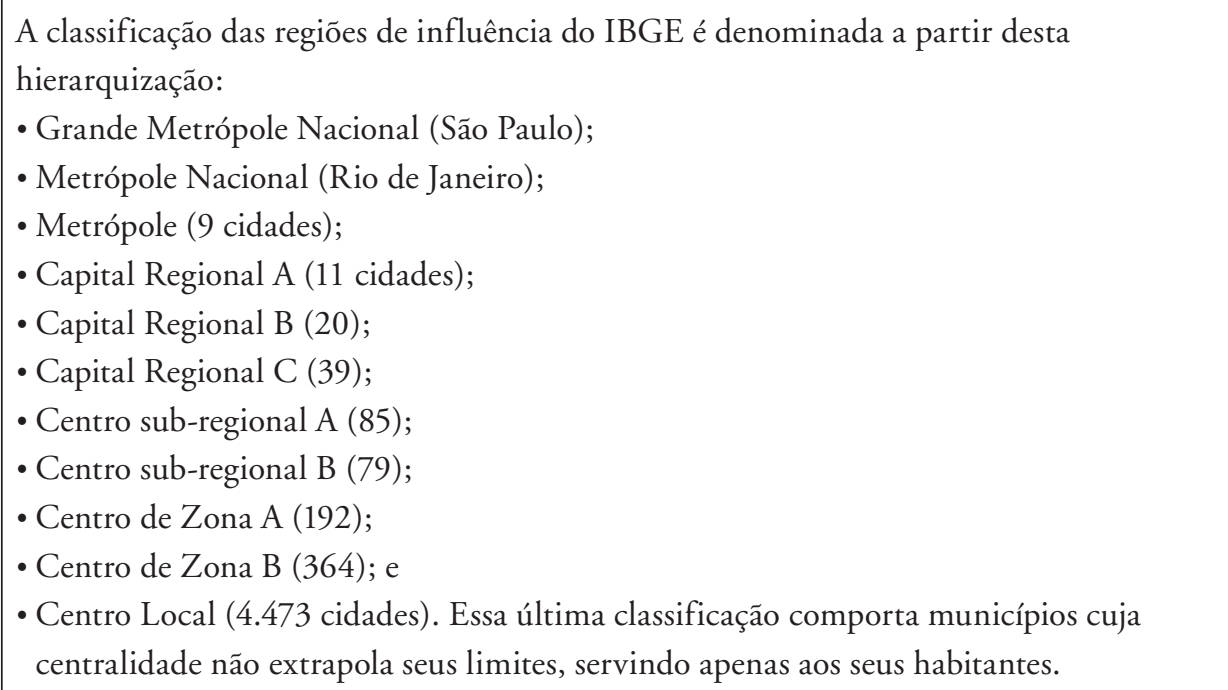

Fonte: IBGE, 2008.

A partir desses estudos, foram definidos os seguintes critérios de inclusão dos municípios para comporem as "rotas da escassez":

i. Municípios das cinco regiões do país;

ii. Municípios com escassez de médicos em dezembro de 2010, dando preferência para municípios classificados com escassez alta e severa.

iii. Municípios denominados "Centro Local" segundo a classificação das regiōes de influência do IBGE, ou seja, cuja centralidade e oferta de serviços públicos e privados não extrapolam os limites do município;

iv. Municípios de micro e pequeno porte, isto é, com até 50 mil habitantes;

v. Municípios que atendessem a critérios de logística e que fossem identificados segundo dificuldade de acesso ou localização geográfica, como municípios de fronteira com outros países, municípios com acesso apenas por via fluvial ou aérea, municípios distantes de grandes centros urbanos, etc.

vi. Nas regiōes Sul e Sudeste, foram selecionados municípios que não fossem vizinhos a municípios com mais de 50 mil habitantes. 
As regiōes Norte e Nordeste tiveram um número maior de rotas por contarem com grandes extensões territoriais, diferentes tipos de transporte (fluvial, terrestre e aéreo), maiores distâncias a serem percorridas e por lidarem com maior concentração de municípios identificados com escassez. No total, foram definidas 10 rotas, somando 36 municípios (tabela 1).

Tabela 1. Número de rotas, municípios e entrevistas das rotas da escassez por região geográfica

\begin{tabular}{|c|c|c|c|c|}
\hline Região & $\begin{array}{l}\text { No de } \\
\text { Rotas }\end{array}$ & UF & $\begin{array}{c}\text { No de } \\
\text { Municípios }\end{array}$ & $\begin{array}{c}\text { No de Médicos } \\
\text { Entrevistados }\end{array}$ \\
\hline Norte & 3 & $\begin{array}{l}\text { Amazonas (AM), Pará } \\
\text { (PA), Rondônia (RO) }\end{array}$ & 10 & 13 \\
\hline Nordeste & 3 & $\begin{array}{l}\text { Bahia (BA), Ceará } \\
\text { (CE), Maranhão (MA), } \\
\text { Pernambuco (PE), Piauí } \\
\text { (PI) }\end{array}$ & 12 & 17 \\
\hline Sudeste & 1 & $\begin{array}{l}\text { Minas Gerais (MG) } \\
\text { (Vale do Jequitinhonha) }\end{array}$ & 3 & 3 \\
\hline Sul & 1 & $\begin{array}{l}\text { Rio Grande do Sul (RS), } \\
\text { Santa Catarina (SC) }\end{array}$ & 5 & 5 \\
\hline Centro-Oeste & 2 & $\begin{array}{l}\text { Mato Grosso (MT), } \\
\text { Mato Grosso do Sul } \\
(\mathrm{MS}), \text { Goiás (GO) }\end{array}$ & 6 & 13 \\
\hline Total & 10 & 14 & 36 & 51 \\
\hline
\end{tabular}

Fonte: EPSM/NESCON/FM/UFMG, 2015.

Uma equipe de seis pesquisadores foi treinada para percorrer as rotas entre os meses de julho de 2011 e março de 2012. Foram realizadas entrevistas semiestruturadas com 51 médicos nos 36 municípios (tabela 1), a partir de um roteiro que contemplava, além de elementos sociodemográficos e de trabalho, questôes em que os sujeitos tiveram oportunidade de discorrer sobre sua trajetória profissional, condiçôes de trabalho atual, percepções acerca do município, expectativas profissionais e sociais, dentre outras questôes. 
Os entrevistados foram informados sobre os objetivos da pesquisa, e aqueles que concordaram em participar assinaram o Termo de Consentimento Livre e Esclarecido, sendo-lhes garantido o sigilo das informações e o anonimato. As entrevistas foram gravadas e posteriormente transcritas.

A análise das entrevistas procurou identificar os principais fatores que influenciaram a decisão dos médicos em se deslocar e permanecer, ou não, trabalhando nos municípios pesquisados. A análise baseou-se na técnica de análise de conteúdo de Bardin (1977). No presente trabalho, foi utilizado o recurso da análise categorial, que iniciou com a leitura do material, buscando-se identificar elementos vinculados com a temática de provimento e fixação dos profissionais de saúde em zonas rurais ou isoladas. Procurou-se, ainda, delinear os assuntos que apareciam com maior frequência para sua posterior codificação.

Em seguida, na fase de exploração do material, escolheram-se as "unidades de registro e de contexto", palavras, frases e temas, que foram agrupados e classificados em categorias e subcategorias. $\mathrm{Na}$ última fase, do tratamento, inferência e interpretação dos resultados, os conteúdos recolhidos foram transformados em dados quantitativos, apresentados nos resultados, incluindo frequência relativa das subcategorias definidas, para a interpretação dos depoimentos das entrevistas realizadas com os médicos. Visava-se identificar um conjunto de fatores relevantes a serem considerados no estudo sobre atração e fixação dos profissionais da saúde em áreas remotas e desassistidas do Brasil.

A pesquisa foi aprovada pelo Comitê de Ética em Pesquisa do Instituto de Medicina Social da Universidade do Estado do Rio de Janeiro - IMS/UERJ (Registro CAAE 0038.0.259.000-11).

\section{Resultado e discussão}

\section{Perfil dos entrevistados}

A maioria dos médicos era do sexo masculino (82,4\%), com idade até 40 anos $(49,1 \%)$, casados $(58,8 \%)$ e com filhos $(64,7 \%)$. Em relação à formação, $25,5 \%$ tinham até cinco e $27,5 \%$ mais de 20 anos de formados; 25,5\% se graduaram fora do Brasil, sendo que a maioria destes foi entrevistada nas rotas do Norte. Mais da metade não possuía curso de especialização (65\%) ou residência médica (55\%). 
A maior parte dos médicos estava sob contrato temporário (63\%) e trabalhava até cinco anos no município visitado (60,8\%). Um pouco mais da metade $(54,9 \%)$ não residia no município e $45 \%$ trabalhavam em outros municípios além do visitado (Tabela 2). Do total de entrevistados, $11 \%$ eram estrangeiros.

Tabela 2. Perfil dos médicos entrevistados nas rotas da escassez

\begin{tabular}{|c|c|c|c|}
\hline & & $\mathbf{N}$ & $\%$ \\
\hline \multirow{21}{*}{ 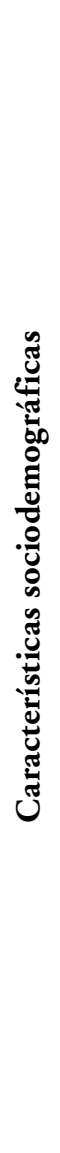 } & Sexo & & \\
\hline & Masculino & 42 & 82,4 \\
\hline & Feminino & 9 & 17,6 \\
\hline & Estado Civil & & \\
\hline & Solteiro & 15 & 29,4 \\
\hline & Casado & 30 & 58,8 \\
\hline & Divorciado & 6 & 11,8 \\
\hline & Faixa etária & & \\
\hline & 20 a 30 anos & 11 & 21,6 \\
\hline & 31 a 40 anos & 14 & 27,5 \\
\hline & 41 a 50 anos & 6 & 11,8 \\
\hline & Mais de 50 anos & 16 & 31,4 \\
\hline & Não respondeu & 4 & 7,8 \\
\hline & Possui filhos & & \\
\hline & Sim & 33 & 64,7 \\
\hline & Não & 11 & 21,6 \\
\hline & Não respondeu & 7 & 13,7 \\
\hline & Local de residência & & \\
\hline & Mora no município pesquisado & 22 & 43,1 \\
\hline & Não mora no município pesquisado & 28 & 54,9 \\
\hline & Não respondeu & 1 & 2 \\
\hline
\end{tabular}




\begin{tabular}{|c|c|c|c|}
\hline & & $\mathbf{N}$ & $\%$ \\
\hline \multirow{19}{*}{ 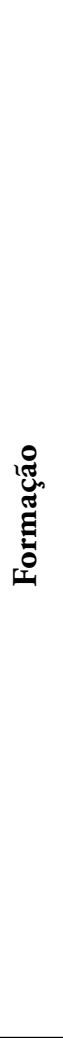 } & \multicolumn{3}{|l|}{ Tempo de formado } \\
\hline & Até 5 anos & 13 & 25,5 \\
\hline & De 6 a 10 anos & 11 & 21,6 \\
\hline & De 11 a 20 anos & 7 & 13,7 \\
\hline & Mais de 20 anos & 14 & 27,5 \\
\hline & Não respondeu & 6 & 11,8 \\
\hline & \multicolumn{3}{|l|}{ Local de formação } \\
\hline & Estado de origem & 21 & 41,2 \\
\hline & Outro estado & 13 & 25,5 \\
\hline & Outro país & 13 & 25,5 \\
\hline & Não respondeu & 4 & 7,8 \\
\hline & \multicolumn{3}{|l|}{ Possui residência médica } \\
\hline & $\operatorname{Sim}$ & 15 & 29,4 \\
\hline & Não & 33 & 64,7 \\
\hline & Não respondeu & 3 & 5,9 \\
\hline & \multicolumn{3}{|l|}{ Possui especialização } \\
\hline & Sim & 20 & 39,2 \\
\hline & Não & 28 & 54,9 \\
\hline & Não respondeu & 3 & 5,9 \\
\hline \multirow{14}{*}{ 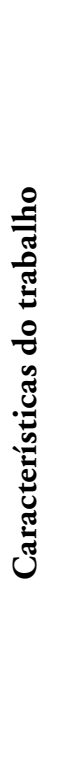 } & \multicolumn{3}{|l|}{ Tipo de vínculo } \\
\hline & Contrato temporário & 32 & 62,7 \\
\hline & Estatutário/CLT & 17 & 33,3 \\
\hline & Não respondeu & 2 & 3,9 \\
\hline & \multicolumn{3}{|l|}{ Tempo de trabalho no município } \\
\hline & Menos de 1 ano & 13 & 25,5 \\
\hline & De 1 a 5 anos & 18 & 35,3 \\
\hline & De 6 a 10 anos & 9 & 17,6 \\
\hline & Mais de 11 anos & 6 & 11,8 \\
\hline & Não respondeu & 5 & 9,8 \\
\hline & \multicolumn{3}{|c|}{ Trabalho em outro município além do pesquisado } \\
\hline & $\operatorname{Sim}$ & 23 & 45,1 \\
\hline & Não & 19 & 37,3 \\
\hline & Não respondeu & 9 & 17,6 \\
\hline
\end{tabular}

Fonte: EPSM/NESCON/FM/UFMG, 2015. 


\section{Análise das entrevistas por categoria}

$\mathrm{Na}$ análise, identificaram-se seis categorias: remuneração, vínculo de trabalho, condiçôes de trabalho, fatores profissionais, fatores locais e fatores pessoais, divididas em 27 subcategorias (Tabela 3). Os entrevistados estão identificados pela sigla do estado seguida por um número de identificação.

Tabela 3. Frequência com que cada categoria e subcategoria apareceu durante as entrevistas

\begin{tabular}{|c|c|c|}
\hline Categorias e subcategorias & $\mathrm{N}$ & $\%$ \\
\hline \multicolumn{3}{|l|}{ Remuneração } \\
\hline Salário & 47 & 92,0 \\
\hline Pagamento em dia & 16 & 32,0 \\
\hline Auxílio-moradia & 9 & 17,6 \\
\hline Auxílio-transporte & 9 & 17,6 \\
\hline Auxílio-alimentação & 8 & 15,0 \\
\hline \multicolumn{3}{|l|}{ Vínculo de trabalho } \\
\hline Vínculo estável & 17 & 34,0 \\
\hline Contrato instável & 13 & 25,0 \\
\hline \multicolumn{3}{|l|}{ Condiçóes de trabalho } \\
\hline Flexibilidade/Folga & 38 & 74,5 \\
\hline Infraestrutura da unidade de saúde & 34 & 66,0 \\
\hline Disponibilidade de equipamentos & 29 & 56,0 \\
\hline Volume de trabalho & 28 & 54,0 \\
\hline Disponibilidade de exames & 26 & 50,0 \\
\hline Disponibilidade de medicamentos & 21 & 42,0 \\
\hline Referência/Médicos Especialistas & 20 & 40,0 \\
\hline \multicolumn{3}{|l|}{ Fatores profissionais } \\
\hline Atualização e capacitação & 18 & 36,0 \\
\hline Residência e especialização & 21 & 42,0 \\
\hline
\end{tabular}




\begin{tabular}{lll}
\hline Categorias e subcategorias & $\mathrm{N}$ & $\%$ \\
\hline Fatores locais & 33 & 64,7 \\
Opções de Lazer & 32 & 62,7 \\
Infraestrutura do município & 30 & 58,8 \\
Distância do município & 28 & 54,9 \\
Acesso ao município & 20 & 39,2 \\
Qualidade de vida & 13 & 25,5 \\
Educação para os filhos & 10 & 19,6 \\
Emprego para o cônjuge & & \\
Fatores pessoais & 34 & 66,0 \\
Origem do profissional & 18 & 36,0 \\
Vínculo social & 17 & 34,0 \\
Reconhecimento da comunidade & 11 & 22,0 \\
\hline Vocação & & \\
\hline
\end{tabular}

Fonte: Estação de Pesquisas de Sinais de Mercado (EPSM/NESCON/FM/UFMG), 2015.

\section{Remuneração}

A categoria "remuneração" incorpora diferentes elementos que compõem a remuneração do profissional no município, como o salário, o pagamento em dia e os auxílios moradia, alimentação e transporte. Quase todos os entrevistados destacaram o "salário" como um dos principais fatores para justificar a atração e/ ou a permanência no município.

Nós procuramos no Google onde oferecia um salário melhor e viemos. Achamos o telefone da Prefeitura e conversamos com a secretária de saúde, e viemos com a cara e a coragem. [MG, 03]

Aqui, é verdade, pode falar que ninguém vem pra ganhar pouco. Salário aqui é o chamariz para os médicos virem. [PA, 04]

Dinheiro, né. O que mais você quer? Não que eu vou trabalhar aqui porque eu gosto do município e tudo. [RO, 04]

Esse achado reflete uma realidade encontrada em países com distintos perfis econômicos, sociais e culturais. Duffrin et al. (2014) chegaram a um resultado 
semelhante em survey realizado com 975 médicos da atenção primária de um estado dos Estados Unidos da América, que apontou a garantia salarial como um fator determinante para a atração de médicos para áreas rurais. Médicos de hospitais rurais de uma província da África do Sul, em estudo conduzido por Kotzee e Couper (2006), defenderam o aumento salarial como um dos fatores mais importantes para retenção de médicos em práticas rurais de trabalho. Estudo conduzido por Dieleman et al. (2003) com profissionais de saúde do Vietnã demonstrou que a situação oposta também ocorre, pois a oferta de salários baixos figura entre os principais fatores que desmotivam os profissionais a trabalharem nessas áreas.

Alguns médicos enfatizaram que o salário é um importante fator de atração, principalmente diante da falta de outros tipos de atrativos no município, como opções de lazer e de serviços, das condições de trabalho e da distância da família, dentre outros.

A dificuldade aqui são as más condições de trabalho, a pouca perspectiva de crescimento profissional. Para fixar um profissional aqui ele tem que ter algum outro tipo de retorno. Se ele não tem um vínculo afetivo com a cidade ele tem que ter ao menos um retorno financeiro. [...] Quanto pior forem as condiçôes de trabalho, quanto mais distante o local da capital, quanto mais difícil for o acesso, eu vejo que a remuneração tem que ser um pouquinho melhor para poder compensar isso. [PE, 01]

Para atrair profissionais tem que ter um salário melhor. Porque aqui a gente se submete a se abster de um shopping, de um teatro, de um cinema, de bons restaurantes. Isso não existe aqui. [RO, 03]

Para Campos e Malik (2008), entretanto, mesmo a oferta de altos salários sendo um importante atrativo, isoladamente, ela não tem garantido a fixação dos médicos em áreas remotas. Nesse sentido, Rodrigues, Silva e Rocha (2010), em estudo sobre atração e fixação de médicos na APS do estado de Minas Gerais, também encontraram que a remuneração mais alta não está associada à fixação de profissionais, além de, paradoxalmente, poder propiciar maior rotatividade dos médicos entre municípios, motivados por melhores propostas salariais.

$\mathrm{O}$ "pagamento em dia" também foi mencionado durante as entrevistas como fator importante para a permanência dos médicos nos municípios.

[...] essa é uma das causas pelas quais muito médicos não ficam, é o pagamento. Os prefeitos assumem um compromisso com os médicos, pagam o primeiro, o segundo mês, no terceiro mês em diante já não pagam, atrasam o salário, se o médico vai cobrar se ofendem [...] [PA, 03]. 
Uma das recomendações da Organização Mundial de Saúde (WHO, 2010)

para melhorar a retenção em áreas rurais é exatamente a utilização de uma combinação de incentivos financeiros fisicamente sustentáveis, como auxíliomoradia e transporte, dentre outros, suficientes para compensar os possíveis custos associados ao trabalho em áreas rurais percebidos pelos profissionais de saúde. $\mathrm{Na}$ fala dos entrevistados, incentivos como os auxílios alimentação, moradia e transporte foram identificados como possíveis fatores de atração e fixação, porém com menor frequência e peso na escolha do médico em trabalhar ou não em determinada localidade.

Pelo menos tem que oferecer uma casa adequada para poder morar, alimentação, essas coisas. A casa não é boa, eu morei bastante tempo aí nesses alojamentos, que só tem um quarto e banheiro, aí não é adequado (...) muita gente, às vezes, por causa disso também decide que não quer vir. [AM, 01]

\section{Vínculo de trabalho}

A categoria "vínculo de trabalho" diz respeito às formas de vinculação estabelecidas entre os profissionais e o município. Os vínculos foram classificados em duas categorias: estáveis, com contrato regido por regime estatutário, vínculo padrão dos servidores públicos na administração pública direta e indireta e pelo regime da Consolidação das Leis do Trabalho (CLT), próprio aos empregados públicos e aos empregados na economia privada; e instáveis, que inclui os contratos temporários com a administração pública, os de prestação de serviços de profissionais autônomos e demais vínculos informais sem proteção ou não plenamente protegidos no âmbito do direito do trabalho (GIRARDI et. al. 2010).

Os vínculos mais comuns dos profissionais entrevistados foram contrato temporário e estatutário. Foi possível identificar nas entrevistas que o tipo de vínculo pode influenciar diretamente na atração e na permanência ou não do médico em uma localidade de trabalho. Parte dos entrevistados enfatizou que o contrato temporário contribui para a atração do profissional ao possibilitar a permanência no município durante um período pré-determinado, sem sanções legais caso o médico opte por deixar o trabalho, além de, em geral, possibilitar uma maior flexibilidade de horário. O contrato temporário permite, por exemplo, que o médico troque de município com facilidade caso receba uma proposta de trabalho mais interessante ou que faça uma poupança, o famoso "pé de meia", até ser aprovado em algum programa de residência médica. 
Nós trabalhávamos aqui dia sim, dia não. Não que a administração quisesse, mas é o que tinha, [...] deixou de ser interessante eu estou indo embora, até mesmo porque eu não sou concursado. [GO, 01]

Tenho contrato temporário. Mas médico gosta dessa regalia, né! [PA, 04]

A estabilidade proporcionada pelo vínculo estatutário foi valorizada por alguns dos médicos entrevistados, principalmente entre aqueles que já atuam há muito tempo na profissão e não têm mais pretensão de fazer residência médica.

Aqui eu sou concursado há quase 20 anos, eu cheguei aqui, eu sou ginecologista, e aí abriu uma vaga para trabalhar no posto de saúde aqui como clínico geral, aí eu fiz o concurso, passei e vamos manter isso aí. [RS, 02]

Nosso problema maior, os salários são defasados. Totalmente defasados. Isso com trinta e três anos de profissão. O que segura aqui é que a gente é concursado [RO, 03].

Segundo Dieleman et al. (2003), o emprego estável também se encontra entre os principais fatores de motivação para profissionais de saúde trabalharem em áreas rurais. Já para Rodrigues, Silva e Rocha (2010), o vínculo estatutário, além de assegurar a permanência dos médicos na APS, é visto pelos profissionais como uma garantia contra demissões por questões políticas.

Apesar da garantia de estabilidade, o vínculo estatuário é rejeitado por alguns entrevistados, principalmente devido ao salário, geralmente inferior ao de médicos que possuem contratos temporários, e à carga horária de 40 horas semanais, utilizada na (ESF). De acordo com Girardi e Carvalho (2003), o alto valor do salário de médicos com contrato temporário, seria na verdade uma forma de compensação à precariedade do vínculo desses profissionais. A Constituição Federal da República (BRASIL, 1988) define, em seu artigo 37, inciso XI, que os subsídios do servidor público municipal não poderão exceder o do prefeito. Por esse motivo, em muitos municípios, os salários oferecidos em editais de concursos públicos não são atrativos para os médicos.

Eu vou dizer por mim, porque meus amigos falam que vão fazer concurso porque é garantia, mas será que o salário vai valer a pena, o salário de concursado é bem menor, o concurso público não me atrai tanto [MA, 03].

\section{Condições de trabalho}

A categoria "condições de trabalho" incorpora diversos fatores que afetam as condições de trabalho do médico: infraestrutura, disponibilidade de equipamentos e materiais, acesso a exames, disponibilidade de medicamentos, possibilidade 
de referência para especialistas e flexibilidade na jornada de trabalho. Um dos aspectos que mais se destacou na fala dos entrevistados foi a dificuldade de desempenhar um bom trabalho em municípios que não disponibilizam infraestrutura de trabalho adequada.

Na verdade há uma dificuldade muito grande de um médico vir pra cá, tem a questão da adaptação e a falta de estrutura para trabalhar, para diagnósticos, para exames mais detalhados. [MA, 03]

Se tiver uma criança que nasce prematura, as incubadoras não funcionam e assim vai. Final de semana aqui é muito difícil ter um convênio com laboratório para fazer os exames. [GO, 02]

Estudo publicado por Ebuehi e Campbell (2011) com profissionais de saúde de práticas rurais e urbanas na Nigéria revelou que, entre aqueles que atuam em áreas urbanas, um dos principais fatores que desencoraja os profissionais a assumirem trabalhos em áreas rurais é a falta de equipamentos e infraestrutura de trabalho.

$\mathrm{O}$ excesso de volume de trabalho foi enfatizado, principalmente, em decorrência da falta de outros médicos, incluindo médicos especialistas e do número elevado de atendimentos diários.

Aqui agora (...) eu sou o único médico. Se tiver alguma ocorrência nos pacientes que já estão internados sou eu que vou ver; e se chegar uma emergência aqui sou eu que vou ver; e se acontecer os dois ao mesmo tempo alguém vai ficar sem atendimento, alguém vai ficar sobrando. [PE, 01]

Aqui médico faz ambulatório, médico faz sutura, médico atende emergência, médico atende parto, médico atende cesárea, quando tem que fazer cesárea. O próprio médico tem que fazer anestesia, tem que fazer a cirurgia [RO, 05].

A "flexibilidade na jornada de trabalho", foi um dos fatores de maior expressão citado pelos médicos nesta categoria. As falas dos entrevistados revelaram que os médicos valorizam a possibilidade de receberem folgas durante a semana, de trabalharem por dias corridos e/ou por produção. Por exemplo, em um município com maior dificuldade de acesso, na região Norte, os médicos trabalhavam, na ocasião, durante 20 dias corridos e folgavam 10. No período da folga, os profissionais trabalhavam em outros municípios, em outros tipos de estabelecimentos de saúde (como hospitais, unidades de pronto-atendimento, consultório particular) ou, no caso dos recém-formados, se dedicavam aos estudos.

Porque nós temos sempre folga, no caso 15 dias aqui e a cada 30 dias, 15 lá. Por exemplo, já passei 60 dias e fiquei 15, 20 dias de folga ou coisa assim. Normalmente é esse incentivo que faz a gente optar por um município né! [PA, 01] 
$\mathrm{Na}$ verdade não foi o primeiro, eu procurei bastante antes, mas a questão é o seguinte, a gente que é recém-formado tem dificuldade de trabalhar no primeiro momento, vai da necessidade de cada um e no meu caso foi justamente isso [...] eu busquei a Saúde da Família porque a carga horária de trabalho, você tem tempo para estudar, você tem tempo para fazer tudo você pode se planejar, tem a flexibilidade que ajuda bastante. [BA, 03]

Para Ebuehi e Campbell (2011), dentre os fatores que podem motivar a atração para prática rural de trabalho, destaca-se a flexibilidade de horário de trabalho. Dados semelhantes foram relatados no estudo de Rodrigues, Silva e Rocha (2010), segundo o qual uma das alternativas que propicia a fixação de médicos é a realização de acordos informais dos profissionais com o município para redução da carga horária semanal. A mesma pesquisa relata, ainda, que a maior parte dos médicos da APS exerce outras atividades, principalmente plantões hospitalares.

\section{Fatores profissionais}

A categoria "fatores profissionais" inclui componentes relacionados à trajetória e expectativa profissional dos médicos. Neste estudo, levantaram-se duas questóes principais: a possibilidade de capacitação/atualização e a pós-graduação por meio de cursos de especialização e residência médica.

Nos discursos analisados, o interesse dos entrevistados, principalmente entre os recém-formados, em realizar cursos de especialização e/ou residência médica foi identificado como fator que dificulta a retenção desses profissionais nos municípios visitados. Esse achado é corroborado pelo estudo de Póvoa e Andrade (2006), que destaca a residência médica como a principal modalidade de pósgraduação escolhida pelos médicos, levando-os a se deslocar para localidades de trabalho que oferecem mais vagas e programas de residência médica. $\mathrm{O}$ estudo de Rodrigues, Silva e Rocha (2010) também aponta que a busca de capacitação, especialmente a residência médica, é um fator que contribui para a rotatividade dos médicos.

Eu sou um profissional em formação, eu preciso fazer a residência médica. [MG, 01]

Eu quero me especializar, e aqui não tem oportunidade de estudo de especialização de cursos, [...] quero morar em Fortaleza que é onde pretendo fazer meus cursos de especialização. [CE, 02]

Dentro dessa premissa, os programas PROVAB e PMM (BRASIL, 2011; BRASIL, 2013), oferecem, além da bolsa, curso de especialização e pontuação 
na prova de residência médica para aqueles que atuarem por no mínimo um ano em área designada pelo Governo Federal. Uma pesquisa com 502 egressos do PROVAB de 2013 revelou que oito em cada 10 entrevistados consideram a bonificação de $10 \%$ na pontuação nos processos seletivos de residência médica como o maior atrativo à participação no programa (EPSM, 2016).

A possibilidade de participar em cursos de atualização e/ou capacitação evidenciada nas entrevistas com os médicos condiz com outros estudos sobre o tema. A oferta de treinamento foi considerada um importante fator motivacional para o trabalho em área rural em estudo com profissionais de saúde de Dieleman et al. (2003) e também por um conduzido por White et al. (2007), que explorou a percepção de 429 médicos que atuavam em áreas rurais e remotas em estado australiano e participaram durante três anos de oficinas de educação médica continuada. Grande parte dos médicos considerava que a participação nessas oficinas era extremamente importante e eficaz para o aumento da confiança na prática, reduzindo o isolamento profissional e aumentando o compromisso de permanecer na área rural e remota.

Acho também que, se o pessoal ficar atendendo, atendendo, eu acho que o médico nunca vai se atualizar, nunca vai melhorar, aprimorar seus conhecimentos. Isso é uma dificuldade que tem aqui. Quase não me deixam ir em [cidade próxima] fazer curso, entendeu? E isso é muito chato. É que eles querem que o médico esteja lá pegando a demanda, atendendo os pacientes, mas eles não estão se importando muito com a qualidade. [AM, 03]

\section{Fatores locais}

A categoria "fatores locais" abrange elementos intrínsecos às localidades e que também influenciam a decisão do profissional em se deslocar e/ou permanecer em uma determinada localidade. Os elementos identificados nesta categoria estão relacionados ao desenvolvimento econômico do município e à sua localização, que incluíram: condiçōes de acesso, distância, infraestrutura do município, oportunidades de lazer, educação de qualidade para os filhos, possibilidade de emprego para o cônjuge e qualidade de vida.

Segundo Rourke (2008), tudo, desde as boas vindas iniciais, o lazer, estilo de vida, emprego para o cônjuge e educação para os filhos, são fatores considerados no processo de escolha de um local de prática. Lehmann, Dieleman e Martineau (2008) apontam que a literatura é inconclusiva sobre o papel individual de cada característica locacional na escolha do profissional em trabalhar em determinado 
município. No entanto, é unânime que a condição de vida em geral é importante para esse processo de tomada de decisão.

A infraestrutura precária do município, que inclui a oferta de serviços básicos (como banco, internet de qualidade...) e de opções de lazer (como disponibilidade de restaurantes, shoppings, cinema, dentre outros), foram assuntos recorrentes entre os entrevistados, configurando-se entre os principais fatores que dificultam a atração e, principalmente, a permanência do profissional no município.

Então, estas são coisas, quando você bota no papel, as pessoas falam assim, "Eu prefiro ganhar a metade e viver em Belo Horizonte que ganhar isso que está aí e viver dentro do pasto". Pode olhar em volta. O que você vê em volta? Só há boi. É queimada, pasto e boi. Só. É para lá, para cá, qualquer lugar que você vai. E poeira. O sol queimando $[\mathrm{RO}, 05]$.

A gente sempre quer comer num lugar melhor e não tem um lugar bom para comer; quer ir para um shopping assistir um cinema. Faz falta, por isso que eu digo que não tenho coragem de morar aqui a vida toda [PI, 02]

O fator "distância" é subjetivo e foi identificado nas entrevistas principalmente em termos de distância da família, amigos e de grandes centros, dificultando a permanência em longo prazo no município pesquisado. $\mathrm{O}$ estudo de Mathews et al. (2011) com médicos graduados de duas universidades canadenses apontou o desejo de estar perto da família e dos amigos como o principal fator que os participantes levaram em consideração ao procurar um local de trabalho

Como aqui no Piauí, ou melhor, no Nordeste inteiro, como falta muito médico, quando a gente vai formando e as propostas vão chegando, aí a gente analisa pelo fator financeiro e a distância. Eu comecei em outra cidade no sul do Piauí, mas era muito longe da família, eu fiquei três meses lá e tem dois meses estou no novo serviço. [PI, 02]

A gente tá longe, eu tô longe de tudo, da minha família. Então também é difícil ficar aqui muito tempo. [PA, 02]

A dificuldade de acesso foi abordada em todas as rotas visitadas e se refere às condições de acesso ao município onde o entrevistado trabalha: se esse acesso é terrestre, pode ser por estrada asfaltada ou de terra, em boas condiçóes ou não; se fluvial, refere-se à disponibilidade, à frequência e à qualidade das embarcações disponíveis; e, se aéreo, refere-se à frequência, tipo, duração de voos e custos associados. Em alguns dos municípios, nas rotas do Norte, os únicos meios de transporte operam por via fluvial ou aérea, em viagens que duram de um a três dias de barco ou que dispóem de poucos voos e de custos elevados. É interessante observar que o Índice de Escassez (EPSM, 2012) apontava, em 
2010, que cerca de 50\% dos municípios da região Norte apresentavam escassez

de médicos, refletindo a dificuldade de atrair e reter médicos para essa região, evidenciada também nas falas dos entrevistados:

Porque se tiver um concurso aqui na prefeitura e tiver um concurso para mim lá em Minas, eu escolho Minas. Por quê? Porque lá eu sei que não tem barco, cara [....]. Não nasci em cima de um barco. Eu vim conhecer barco agora no Amazonas. Mas o meu medo é esse. Porque qualquer coisa que acontecer comigo ou com minha família, ou eu saio de avião daqui ou eu saio de barco. Qualquer um dos dois é difícil. O avião custa muito caro e o barco porque demora, poxa. Então eu acho que a estrada é um meio mais fácil de transporte. A logística é mais fácil. [AM, 04]

Para aqueles profissionais casados e/ou com filhos, a disponibilidade de escola de qualidade para os filhos e de emprego para o cônjuge foram identificados nas entrevistas como fatores que podem determinar a atração e fixação do profissional. Póvoa e Andrade (2006) encontraram resultados semelhantes em estudo com médicos. Para os autores, a "oportunidade de emprego para o cônjuge pode influenciar diretamente na escolha locacional dos médicos, principalmente para aqueles parceiros que possuem níveis mais elevados de escolaridade”. A presença de escolas de qualidade para os filhos também é um fator determinante para escolha do local de trabalho, identificado por Lehmann, Dieleman e Martineau (2008).

Tinha plano de me fixar, tanto que comprei casa, terreno, procurei investir o que eu ganhei aqui, mas as coisas mudaram e eu vi que não é viável isso. Principalmente pela minha filha, ela começa a se desenvolver e precisa de uma escola de qualidade. [MS, 05]

É, na verdade a gente traça planos no seguinte: se ela [esposa] conseguir uma posição satisfatória pra trabalhar aqui ela vem; se não, eu que vou pra onde ela for. [PA, 04]

Alguns profissionais atribuíram ainda a qualidade de vida à permanência no município visitado, que se refere ao fato de os médicos valorizarem qualidade de vida, segurança e a tranquilidade que o município oferece. O estudo de Wasko, Jenkins e Meili (2014), com 62 médicos de uma província canadense, também identificou, entre os principais fatores de atração de médicos, a preferência por um estilo de vida rural e o sentimento de segurança.

O que a gente sente falta é de uma escola de qualidade, um pouco mais de diversão, uma loja boa, algum lugar para você se distrair, esfriar a mente um pouco. Mas por outro lado é muito bom, nunca fui roubado, nunca fui assaltado, deixo o meu carro na rua e ninguém mexe, todo mundo conhece a gente, a população em geral te respeita muito, tem muita consideração (...). A minha filha anda de bicicleta na rua, tem as amiguinhas dela, vai andando para a escola, volta, coisa que jamais seria possível em outra cidade. [MS, 05] 


\section{Fatores pessoais}

Finalmente, a categoria "fatores pessoais" congrega os aspectos relacionados à experiência e/ou vivência individual dos médicos entrevistados que influenciam sua escolha em se deslocar e/ou permanecer em determinada localidade de trabalho. São eles: "origem/família", "vínculo social", "reconhecimento da comunidade" e "vocação".

A correlação entre a origem do profissional e sua escolha locacional de prática é muito discutida na literatura e foi um dos fatores de maior frequência identificado nas entrevistas. Wasko, Jenkins e Meili (2014) destacaram que a origem rural do profissional configura-se entre os principais fatores de retenção de médicos em áreas rurais. Um survey conduzido por Costa et al. (2006) com 1.578 residentes do terceiro ano de residência de diversos programas em Medicina de Família nos Estados Unidos revelou que mais de 50\% dos residentes preferem trabalhar em comunidades do mesmo porte daquelas nas quais cresceram. Similarmente, o survey conduzido por Duffrin et al. (2014) apontou que o porte do município de criação do profissional é altamente associado ao trabalho em área rural. Estudos de revisão sobre o tema igualmente apontam que médicos nascidos em área rural têm mais chances de optarem por trabalhar em áreas rurais (WILSON et al., 2009; LEHMANN; DIELEMAN; MARTINEAU, 2008; LAVEN; WILKINSON, 2003). Póvoa e Andrade (2006) apontam, ainda, que a origem do cônjuge é um importante fator que contribui para a fixação de médicos.

E eu queria seguir no meu município, saí para estudar e voltei para a minha terra. Ficar em Porto Alegre nunca foi do meu interesse. [RS, 01]

Assim que eu terminei a faculdade eu queria voltar para minha cidade, acho que desde que eu comecei a faculdade eu queria voltar. Pelos vínculos familiares, de amizade, e eu gosto do estilo de vida do interior, é menos estressante. São vários fatores, minha esposa é daqui, minha família é daqui. [PE, 01]

Estudo realizado por Chan et al. (2005) com 382 médicos que atuam em área rural indicou que, apesar da forte relação entre a origem rural do profissional e sua decisão em atuar em área rural, médicos de origem urbana ainda são a principal fonte de recursos humanos nessas áreas. Esse estudo, assim como o de Rourke et al. (2005), aponta que a exposição de médicos que cresceram em grandes centros a cenários de práticas rurais durante a graduação e pós-graduação influencia sua decisão de atuar em comunidades rurais. 
Alguns profissionais ressaltaram ainda como relevantes para a atração e permanência nos municípios visitados o estabelecimento e manutenção de novos vínculos sociais, principalmente diante da falta de opções de lazer; o reconhecimento do trabalho pela comunidade; e a vocação para o trabalho na APS, principalmente em comunidades mais carentes e desassistidas. $\mathrm{O}$ estudo conduzido por Wasko et al. (2014) revelou de modo similar a valorização dos pacientes como um dos fatores de maior relevância para a fixação dos profissionais em área rural. Ney e Rodrigues (2012), na mesma linha, defendem que os fatores que estimulam a continuidade do profissional na APS são o reconhecimento e os vínculos estabelecidos com a comunidade, além da identificação com a própria filosofia da ESF.

Eu sempre tive, desde o início, afinidade pelo atendimento a saúde básica, à saúde da família. Então gosto muito do contato com o paciente, da relação com o paciente que a gente tem, isto contribui muito. (RO, 02)

\section{Considerações finais}

Este estudo aponta que não existe uma fórmula única para promover a atração e fixação de médicos em áreas remotas e desassistidas. Ainda que o salário tenha sido um atributo mencionado por quase todos os entrevistados, o estudo aponta para a importância de se combinar incentivos financeiros e não financeiros, como flexibilidade e folga no trabalho, infraestrutura da unidade de saúde e oportunidade de capacitação/atualização, dentre outros, na elaboração de estratégias de atração e fixação de profissionais. Entretanto, foram levantados fatores importantes que embasam a decisão do profissional em se deslocar e/ou permanecer em determinado trabalho, mas que não expressam necessariamente uma linearidade, sendo muitos deles de origem subjetiva, imponderáveis e incontroláveis, como os fatores pessoais e locais.

Os programas de provimento de médicos lançados durante os últimos anos, PROVAB e PMM, baseiam-se nessa perspectiva, combinando diferentes tipos de incentivos, como financeiros, cursos de especialização, ajuda de custo e bonificação na prova de residência. Contudo, esses programas, apesar de atraírem o profissional, podem não ser suficientes para fixá-los. É o caso do PROVAB, que estimula o médico a uma prática já existente, a de trabalhar na APS até ser aprovado em um programa de residência médica. 
De fato, atrair e fixar médicos é um problema complexo, envolto em motivações intrínsecas e extrínsecas que influenciam a escolha do local de atuação do profissional. $\mathrm{O}$ estudo de estratégias que levem em consideração os fatores condicionantes para a atração e fixação de profissionais deve ser um exercício constante entre os planejadores de recursos humanos em saúde, de modo a subsidiar a tomada de decisóes baseadas em evidências. ${ }^{1}$

\section{Agradecimentos e financiamento}

Aos pesquisadores que contribuíram com a coleta de dados e aos profissionais de saúde que participaram da pesquisa. Este estudo foi financiado pelo Ministério da Saúde (MS)/Organização Pan Americana de Saúde (OPAS) -Número da Carta Acordo: BR/LOA/110003.001

\section{Referências}

BARDIN, L. Análise de conteúdo. Lisboa: Edições 70, 1977. 225 p.

BRASIL. Constituição da República Federativa do Brasil. Brasília, DF. Senado, 1988. - Portaria Interministerial no 2.087, de $1^{\text {o }}$ de setembro de 2011. Institui o

Programa de Valorização do Profissional da Atenção Básica. Diário Oficial da União, Brasília, 2 set. 2011.

Lei no 12.871, de 22 de outubro de 2013. Institui o Programa Mais Médicos, altera as Leis no 8.745, de 9 de dezembro de 1993, e no 6.932, de 7 de julho de 1981, e dá outras providências. Diário Oficial da Uniāo, Brasília, 23 out. 2013,

CHAN, B.T.B. et al. Factors influencing family physicians to enter rural practice: Does rural or urban background make a difference? Can. Fam. Physician., v. 51, n. 9, p. 12461247, 2005.

CONSELHOREGIONALDEMEDICINADOESTADODESÃOPAULO(CREMESP). Demografia Médica no Brasil 2015. São Paulo: CREMESP/CFM, 2015. Disponível em: <http://www.usp.br/agen/wp-content/uploads/DemografiaMedica30nov2015.pdf>. Acesso em: 21 ago. 2016.

CAMPOS, C. V. A.; MALIK, A. M. Satisfação no trabalho e rotatividade dos médicos do Programa de Saúde da Família. Rev. Adm. Publica, v. 42, p. 347-68, 2008.

CAMPOS, F. E.; MACHADO, M. H.; GIRARDI, S. N: A fixação de profissionais de saúde em regiōes de necessidades. Saúde para Debate, n. 44, p. 13-24, 2009.

COSTA, A.J. et al. To stay or not to stay: factors influencing family practice residents' choice of initial practice location. Fam. Med., v. 28, n. 3, p. 214-219, 2006. 
DIELEMAN, M. et al. Identifying factors for job motivation of rural health workers in

North Vietnam. Journal of Human Resources for Health, v. 1, n. 10, p. 1-10, 2003.

EBUEHI, O.M.; CAMPBELL, P.C. Attraction and retention of qualified health workers to rural areas in Nigeria: a case study of four LGAs in Ogun State, Nigeria. Rural and Remote Health, v. 11 n. 1, p. 1515, 2011.

ESTAÇÃO DE PESQUISA DE SINAIS DE MERCADO (EPSM). Identificação de Áreas de Escassez de Recursos Humanos em Saúde no Brasil. Belo Horizonte: EPSM/NESCON/ FM/UFMG; 2012. Disponível em: < <http://epsm.nescon.medicina.ufmg.br/epsm/ Relate_Pesquisa/Identifica\%C3\%A7\%C3\%A3o\%20de\%20\%C3\%A1reas\%20de\%20 escassez\%20de\%20RHS\%20no\%20Brasil.pdf>. Acesso em: 25 set. 2015.

. Avaliação e análise do perfil dos Médicos egressos do PROVAB 2013 e das percepçôes sobre a experiência de participação no Programa. Belo Horizonte: EPSM/NESCON/FM/ UFMG. 2016. Disponível em: <http://epsm.nescon.medicina.ufmg.br/epsm/Relate_ Pesquisa/Relatorio_PROVAB2013.pdf>. Acesso em: 8 ago. 2016.

. Dimensionamento da estrutura e dinâmica do mercado de trabalho em Atenção Básica em Saúde. Belo Horizonte: EPSM/NESCON/ FM/UFMG, 2014. Disponível em: <http:// epsm.nescon.medicina.ufmg.br/epsm/Relate_Pesquisa/Dimensionamento $\% 20 \mathrm{da} \% 20$ estrutura $\% 20 \mathrm{e} \% 20 \mathrm{din} \% \mathrm{C} 3 \%$ A 2 mica $\% 20$ do $\% 20$ mercado $\% 20$ de $\% 20$ trabalho $\% 20$ em\%20AB\%20em\%20Sa\%C3\%BAde\%20(Rel\%20Final).pdf>. Acesso em: 25 set. 2015. FUNDAÇÃO GETÚlIO VARGAS (FGV). Escassez de Médicos. Rio de Janeiro: Centro de Políticas Sociais, 2008. Disponível em: <http://www.cps.fgv.br/ibrecps/medicos/index. htm>. Acesso em: 25 set. 2015.

GOVERNMENT ACCOUNTABILITY OFFICE. Health professional shortage areas: problems remain with primary care shortage area designation system. Washington: GAO, 2006. Disponível em: <http://www.gao.gov/new.items/d0784.pdf>. Acesso em: 25 set. 2015. GIRARDI, S. N. et al. O trabalho precário em saúde: tendências e perspectivas na Estratégia da Saúde da Família. Divulgação em Saúde para Debate, v. 45, p. 11-23, 2010.

GIRARDI, S. N. et al. Índice de Escassez de Médicos no Brasil: estudo exploratório no âmbito da atenção primária. In: PIERANTONI, C.R; DAL POZ, M. R.; FRANÇA, T. O. (Org.) O Trabalho em Saúde: abordagens quantitativas e qualitativas. Rio de Janeiro: CEPESC/IMS/UERJ-ObservaRH, 2011. p. 171-186.

GIRARDI, S. N.; CARVALHO, C. L. Contratação e qualidade do emprego no Programa de Saúde da Família no Brasil. In: FALCÃO, A. et al. (Org.). Observatório de recursos humanos no Brasil. Rio de Janeiro: Fiocruz, 2013. p. 157-190.

INSTITUTO BRASILEIRO DE GEOGRAFIA E ESTATÍSTICA (IBGE). Regioes de Influência das Cidades 2007. Rio de Janeiro: IBGE; 2008. Disponível em: <http://www. ibge.gov.br/home/geociencias/geografia/regic.shtm>. Acesso em: 25 set. 2015. 
KOTZEE, T. J.; COUPER, I. D. What interventions do South African qualified doctors think will retain them in rural hospitals of the Limpopo province of South Africa? Rural and Remote Health, v. 6, n. 3, p. 581, 2006.

LAVEN, G.; WILKINSON, D. Rural doctors and rural backgrounds: How strong is the evidence? A systematic review. Australian Journal of Rural Health, v. 11, n. 6, p. 277-284, 2003. LEHMANN, U.; DIELEMAN, M.; MARTINEAU, T. Staffing remote rural areas in middle-and low-income countries: a literature review of attraction and retention. BMC health services research, v. 8, n. 1, p. 19, 2008.

MACIEL FILHO, R. Estratégias para a distribuição e fixação de médicos em sistemas nacionais de saúde: o caso brasileiro. 2007. 262 f. Tese (Doutorado em Saúde Coletiva) - Instituto de Medicina Social, Universidade do Estado do Rio de Janeiro, Rio de Janeiro. 2007.

MATHEWS, M. et al. Generational differences in factors influencing physicians to choose a work location. Rural and Remote Health, v. 12, p. 1864, 2012.

NEY, M. S.; RODRIGUES, P. H. A. Fatores críticos para a fixação do médico na Estratégia Saúde da Família. Physis, v. 22, n. 4, p. 1293-1311, 2012.

PÓVOA, L.; ANDRADE, M. V. Distribuição geográfica dos médicos no Brasil: uma análise a partir de um modelo de escolha locacional. Cadernos de Saúde Pública, Rio de Janeiro, v. 22, n. 8, p. 1555-1564, 2006.

RODRIGUES, R. B.; SILVA, N. C.; ROCHA, T. A. H. Atração e retenção do profissional médico e os desafios para a Estratégia Saúde da Família. In: XXXIV Encontro da ANPAD. Rio de Janeiro, 2010. Disponível em: <http://www.anpad.org.br/admin/pdf/gpr2161.pdf>. Acesso em: 21 ago. 2016.

ROURKE, J. T. Increasing the number of rural physicians. CMAJ, v. 178, n. 3, p. 322325, 2008.

ROURKE, J. T. et al. Relationship between practice location of Ontario family physicians and their rural background or amount of rural medical education experience. Can J Rural Med. v. 10, n. 4, p. 231-240, 2005.

WASKO, K.; JENKINS, J.; MEILI, R. Medical practice in rural Saskatchewan: factors in physician recruitment and retention. Can J Rural Med., v. 19, n. 3, p. 93-98, 2014.

WILSON, N. W. et al. A critical review of interventions to redress the inequitable distribution of healthcare professionals to rural and remote areas. Rural Remote Health, v. 9, n. 2, p. 1060, 2009.

WHITE, C. D. et al. Making a difference: education and training retains and supports rural and remote doctors in Queensland. Rural and Remote Health, v. 7, n. 2, p. 700, 2007. WORLD HEALTH ORGANIZATION (WHO). Increasing access to health workers in remote and rural areas through improved retention. Global recommendations. Geneva: WHO, 2010. 
${ }^{1}$ A.C.S. van Stralen e A.W. Massote contribuíram na coleta, análise e interpretação dos dados, redação do artigo, revisão crítica relevante do conteúdo e aprovação da versão a ser publicada. C.L. Carvalho e S.N. Girardi contribuíram na concepção do projeto, revisão crítica relevante do conteúdo e aprovação da versão a ser publicada. 


\section{Physician's perception on attracting and retaining factors in remote and underserved areas: shortage route}

The shortage and the maldistribution of physicians are severe and persistent problems in Brazil. Knowning what attracts and especially what retains these professionals in remote and underserved areas is essential to guide public policies aimed at this issue. This study investigated the main factors that attract and retain physicians in municipalities with shortage of physicians, composing the so-called "Shortage Routes"; 51 doctors in 10 routes covering the five regions of Brazil were in-depth interviewed. The content analyses identified six categories: wages, employment relationship, working conditions, work-related factors, local factors and personal factors, disaggregated in 27 subcategories; highlighting items as salary, flexibility of working hours, health facilities infrastructure, origin of the professional and infrastructure and leisure options in the city. The results show the importance of combining different incentives, financial and nonfinancial to attract doctors to remote and underserved areas.

> Keywords: shortage; physician; primary care; public health. 